\title{
Management of premature rupture of membranes at Sohag University Hospital: a clinical audit
}

\author{
Salah M. Rasheed (M.D); Mohamed N. Salem (M.D); Magdy A. \\ Mohamed (M.D) and Ahmed M. Fahmy (M.B.B.Ch) \\ Obstetrics and Gynaecology, Faculty of Medicine, Sohag University, \\ Egypt
}

\begin{abstract}
Background: Premature Rupture of membranes is not unusual yet the management is contentious, even at term. When it happens in a pregnancy that approaches full term, labor is expected to start naturally, without surgical or medical support. Expectant management was used where the rate of surgical intervention was greater, without rising in the perinatal and maternal complications. Clinical audit is a process of quality improvement which aims to improve patient care and outcomes by systematically reviewing care against specific standards and reviewing change.

Objectives: All cases of PROM at Sohag University Hospital were recruitted for auidt management.

Patients and methods: 73 cases were enrolled over a period of 6 months from February 2019 to August 2019.

Results: The main results of the study were identifying areas with nearly optimal care and areas with substandard care in the management of cases with PROM at Sohag University Hospital. They enabled the assessment of the practice at the Sohag University Hospital to see if this meets the recommended clinical practice guidelines (CPG).

Conclusion: Rupture of fetal membranes once has occurred, the debate lies regarding whether or not to deliver the baby according to the gestational age. Careful identification of present or possible complications, and each case should be dealt with separately based on gestational age and the presence or likelihood of these complications currently holds best hopes for optimizing fetal and maternal outcome in PROM patients.
\end{abstract}

Key Words: premature rupture of membranes, chorioamnionitis, clinical audit.

\section{INTRODUCTION}

Premature rupture of membranes (PROM) refers to fetal membrane rupture before the beginning of labor and can happen at any gestational age ${ }^{(\mathbf{1})}$. It complicated 4.5 percent of pregnancies, accounting for 32.6 percent of preterm births ${ }^{(2)}$.

Premature fetal membrane rupture is a clinical diagnosis; confirmatory speculum inspection showing pooling of fluid in the vagina and coming from the cervix, ferning of dried secretions found under a microscope, known as arborization (historical) and fluid alkalinity as determined by the Nitrazine paper test ${ }^{(3)}$.

Antenatal glucocorticoid administration decreases the incidence of RDS, IVH, and necrotizing enterocolitis by around 50 percent if given to women with intact membranes threatening preterm labor ${ }^{(\mathbf{1}) \text {. }}$ 
Give cases with P-PROM oral erythromycin $250 \mathrm{mg}$ to women 4 times a day for up to ten days or until the delivery ${ }^{(4)}$.

A 4-time increase in perinatal deaths and a 3-time increase in neonatal morbidity, including respiratory distress syndrome, intra-amniotic infection, and intraventricular hemorrhage are associated with preterm PROM $^{(5)}$.

Maternal complications:

Intra-amniotic infection, which occurs in 13 percent to 60 percent of cases with preterm PROM versus $1 \%$ on a full term, and postpartum endometritis, which happens in 2 percent to 13 percent of cases with preterm PROM. Chorioamnionitis is more usually seen in cases with a long duration of PPROM $^{(6)}$.

This work is aiming at:

1) Auditing the current management of RPOM.

2) Identifying the gap between current practice and ideal practice.

3) Setting recommendations for filling the gap to improve patient satisfyaction, neonatal and maternal outcome and minimize complications.

\section{PATIENTS AND METHODS}

An observational study was conducted at Sohag University Hospital on all patients with RPOM.

Inclusion criteria:

Patients with PROM with gestational age ranging from 28 weeks to 34 weeks.

Exclusion criteria:

- Preterm labor.

- Coexisting medical disease.

- Multifetal pregnancy.

Methods:

The following data were recorded: patient's demographic data and patient's menstrual, obstetric, family, medical and surgical histories. During the current pregnancy, the following data were collected: Gestational age at diagnosis of PROM, Blood pressure, pulse and temperature, sterile Cusco speculum examination to detect wither there is leakage of fluid from cervix or not, baseline investigations include complete blood picture, C-reactive protein, urine analysis, Rhesus factor and blood grouping for primigravida and serum glucose for mother and transabdominal ultrasonography for assessment of fetal gestational age, AF volume, placental localization, and grading. Antepartum fetal monitoring included NST and biophysical profile.

Then, the management plan according to hospital practice includes:

1- Induction of lung maturation by steroids, prophylaxis against infection by antibiotics (clindamycin 300 twice daily for 10 days and IV cefotaxime $1 \mathrm{gm}$ ),

2- On discharge, the followings were recorded:

Duration of hospital stay, Treatment that will be administered at home and Instructions were given to the patient.

Clinical practice guidelines of PROM at time of audit:

- Review history (medical, surgical, obstetric and social).

- Assess for signs and symptoms.

- Physical examination.

Diagnosis:

In a woman showing possible signs of P-PROM, provide a speculum evaluation to check for amniotic fluid pooling.

Do not rely only on the results of insulin-like growth factor-binding protein-1 or placental alpha-microglobulin-1 tests to decide the plan of management of PROM cases, but also her clinical condition, medical history, and pregnancy, and gestational age should be considered.

Nitrazine test shouldn't be used to diagnose premature fetal membrane rupture. 
Antenatal prophylactic antibiotics for women with P-PROM:

1. Offer cases with P-PROM oral erythromycin $250 \mathrm{mg} 4$ times a day for up to 10 days or until the woman is in confirmed labor.

2. For women with P-PROM who cannot tolerate erythromycin or there is a contraindication of erythromycin, use oral penicillin for up to 10 days, or until the woman is in confirmed labor.

3. Co-Amoxiclav shouldn't be used for prophylaxis against infection in cases with fetal membranes rupture.

\section{Diagnosis of intra-amniotic infection in the case of fetal membrane rupture:}

In order to diagnose intrauterine infection in women with fetal membrane rupture, use a combination of clinical evaluation and tests $(\mathrm{C}$ reactive protein, total leukocytes count, and fetal heart rate measurement using cardiotocography).

\section{RESULTS}

Table (I) shows that the mean value of the heart rate was $99.73 \pm 9.58$ and ranged $(80-120)$ with the mean value of body temperature was $37.14 \pm 0.33$ ranged $(36.8-38)$.
Figure (1) shows that the majority of our cases $66(90.41 \%)$ the Non-stress test was reactive versus non-reactive in only $7(9.59 \%)$.

Table (II) shows that the mean value of the latency period was $20.1 \pm 13.73$ and ranged $(1-60)$. The majority of cases $63(86.3 \%)$ delivered by CS and only $10(13.7 \%)$ had a normal vaginal delivery. The cause of CS delivery was PROM in 34 weeks of gestation $(50.68 \%)$ of cases, $16(21.92 \%)$ had contractions, $8(10.96 \%)$ had chorioamnionitis while $5(6.85 \%)$ either due to Fetal distress or placental separation and $1(1.37 \%)$ either due to breech or retroplacental hematoma.

Table (III) shows that $71(97.26 \%)$ of cases received steroid therapy, but the majority of cases did not receive tocolytic therapy 53 (72.6\%).

Table (IV) shows that there was a nonsignificant difference between patients groups received tocolysis and those not received tocolytic therapy in latency periods $(20.9 \pm 12.63 \& 19.79 \pm 14.23$ respectively $\& \mathrm{p}=0.527$ ). Also, $55 \%$ and $58.5 \%$ of received tocolysis and those not received tocolytic therapy respectively admitted to NICU without signifycant difference between patients groups $\mathrm{p}=0.788$.

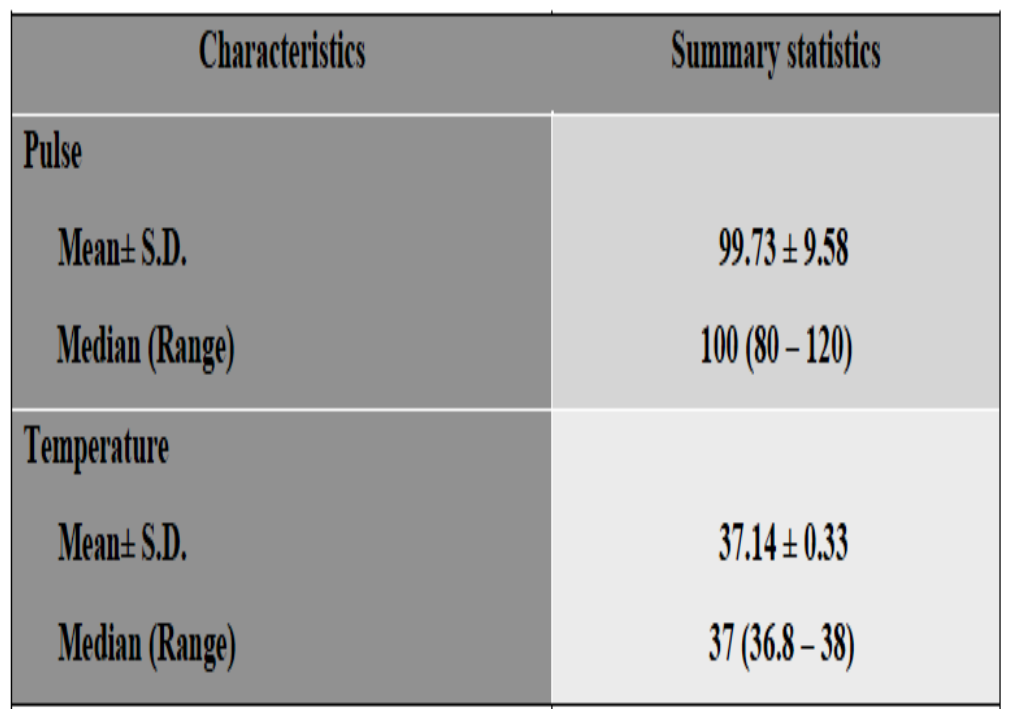

Table (I): Distribution of the studied patients according to clinical data: 
SOHAG MEDICAL JOURNAL

Vol. 24 No. 2 April 2020

\begin{tabular}{|c|c|}
\hline Latency, mode and cause of delivery & $\mathrm{N}_{0}(\%)$ \\
\hline \multicolumn{2}{|l|}{ Latency (days) } \\
\hline Mean \pm S.D. & $20.1 \pm 13.73$ \\
\hline Median (Range) & $18(1-60)$ \\
\hline \multicolumn{2}{|l|}{ Mode of delivery } \\
\hline Cesarean section & $63(86.3 \%)$ \\
\hline Normal vaginal delivery & $10(13.7 \%)$ \\
\hline \multicolumn{2}{|l|}{ Cause of termination of pregnancy } \\
\hline Breech & $1(1.37 \%)$ \\
\hline Chorioamnionitis & $8(10.96 \%)$ \\
\hline Active in labor & $16(21.92 \%)$ \\
\hline Fetal distress & $5(6.85 \%)$ \\
\hline Placental separation & $5(6.85 \%)$ \\
\hline 34 weeks of gestation & $37(50.68 \%)$ \\
\hline Retroplacental hematoma & $1(1.37 \%)$ \\
\hline
\end{tabular}

\begin{tabular}{|l|c|}
\hline \multicolumn{1}{|c|}{ Drugs used } & No (\%) \\
\hline Steroids & \\
No & $2(2.74 \%)$ \\
Yes & $71(97.26 \%)$ \\
\hline Tocolysis (S04) & \\
No & $53(72.6 \%)$ \\
Yes & $20(27.4 \%)$ \\
\hline Antibiotics & \\
Dalacin & $64(87.67 \%)$ \\
Dalacin + IV Cefotax & $9(12.33 \%)$ \\
\hline
\end{tabular}

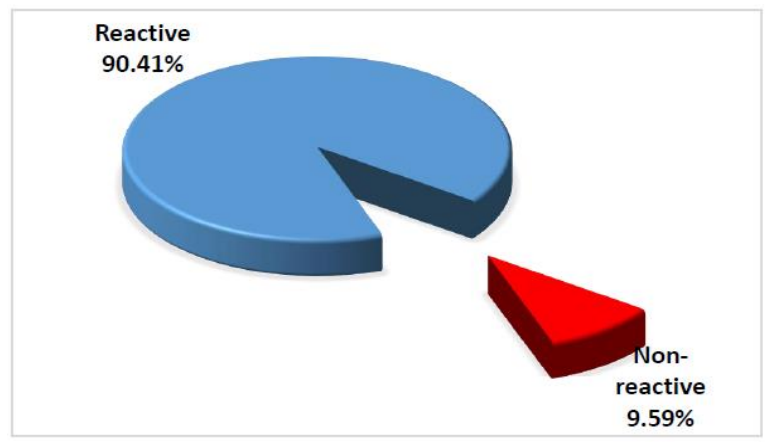

Table (II): latency, Mode of delivery and cause of termination of pregnancy

Table (III): The percentage of the studied cases according to drugs used :
Figure (1): Results of the nonstress test:

\begin{tabular}{|c|c|c|c|}
\hline \multirow[t]{2}{*}{ Variables } & \multicolumn{2}{|c|}{ Tocolysis } & \multirow[t]{2}{*}{ P-value } \\
\hline & $\begin{array}{c}\text { No } \\
\text { (N.=53) }\end{array}$ & $\begin{array}{c}\text { Yes } \\
(\mathbf{N} .=20)\end{array}$ & \\
\hline \multicolumn{4}{|l|}{ Latency (weak) } \\
\hline Mean \pm S.D. & $19.79 \pm 14.23$ & $20.9 \pm 12.63$ & $0.527^{*}$ \\
\hline Median (range) & $14(2-60)$ & $22.5(1-42)$ & \\
\hline \multicolumn{4}{|c|}{ Admission to neonatal ICU } \\
\hline No & $22(41.5 \%)$ & $9(45 \%)$ & 0.788 \\
\hline Yes & $31(58.5 \%)$ & $11(55 \%)$ & \\
\hline
\end{tabular}

P-value was calculated by Chi Square Test

* P-value was calculated by Mann Whitney Test
Table (IV) : Relation between latency period, admission to neonatal ICU and tocolysis: 


\section{DISCUSSION}

PPROM condition is a serious clinical issue that complicates approx. 3 percent of all pregnancies and causes forty percent of all preterm deliveries (7).

Once fetal membrane rupture has occurred neither the exact time of delivery can be expected nor it is possible to expect infection will happen or not. Fetal membranes rupture results in spontaneous labor and delivery in a large number of women within 7 days, without interference. Premature prelabour membrane rupture per se is also considered a risk factor for maternal and fetal infections (8).

We conducted this observational study to auditing the current management of fetal membrane rupture in the Obstetrics and Gynecology department, Sohag University hospital, identifying the gap between the current practice and ideal practice and setting recommendations for filling the gap to improve patient satisfaction, neonatal and maternal outcome and minimize complications.

In our study the mean age of our cases was $27.67 \pm 5.94$ ranged $(17-38)$. The correlation of PPROM in pregnant women > 25 years of age can be explained by endogenous changes in the fetus and its annexes, as the occurences of fetal aneuploidy with growing maternal age are greater.

This was comparable to the study done by Mukharya $\mathbf{J}$ and Mukharya $\mathbf{S}{ }^{\left({ }^{(9)} \text {, }\right.}$ which showed similarity to the results by Rawat et al. ${ }^{(10)}$ who found that the mean age was $24.00 \pm 2.77$ years for cases of PROM. (Rawat et al., 2018)

In agreement with us, the average age in a study by Sultana et al. (11) was $27.8 \pm 4.9$ years with the range (20-44). Most of the cases 38(61.3\%) were above 26 years. Also, Aris et al. (12) reported that cases with PPROM were more likely to be under 20 years old. Under review among them, 526 cases of fetal membrane rupture;
Abdoulfattah and Ezzat ${ }^{(13)}$ The age of the patients was found to range from 20-37 years with an average age of 28.5 years by Abdoulfattah and Ezzat ${ }^{(13)}$. Assefa et al. ${ }^{(14)}$ found that the median age of the women for the case was $27(\mathrm{IQR}=5)$.

In our study, $19.18 \%$ were primigravida while the majority (46.58\%) was P $1-2,(30.14 \%)$ and $(4.11 \%)$ was P 3-4 or $\mathrm{P} \geq 5$.

As regards the parity of the patients $19.18 \%$ were primigravida these results are less than the results reported by Rawat et al. (10) who found that $54 \%$ were primigravida.

But our results still lower than Sultana et al. ${ }^{(11)}$. 62 patients were enrolled in the study Approximately 51 (82.3\%) were primigravida and virtual primigravida.

Our results were similar to Dars et al. (15) who also reported PPROM more in primigravidae.

In our study, gestational age at the time of presentation was $31.04 \pm 1.72$ (28 $34)$, and the majority (68.49\%) was 29 - 32 weeks and $(23.29 \%)$ of them aged 33 - 34 weeks.

Similar results were reported by Pharande et al. (16), the mean gestational age (GA; 26 weeks) in the Early-PPROM group.

In our study, the majority of our cases (58.9 \%) didn't have a previous cesarean section, $(10.96 \%, 17.81 \%$ \& 12.33 had one, two and three previous CS. Assefa et al. ${ }^{(14)}$ also found the cesarean section to be a remarkable risk factor. Cases with previous CS were 3.15 times more prone to developing PROM than those that did not have a previous CS. This may be due to the increased risk of CS scar rupture durin$\mathrm{g}$ the subsequent pregnancy.

In our study, the mean value of heart rate was $99.73 \pm 9.58$ and ranged $(80-$ 120 ) with a mean value of body 
temperature was $37.14 \pm 0.33$ ranged $(36.8-38)$

Similar results were reported by Giles et al. ${ }^{(17)}$ as fever (temperature greater than $37.8^{\circ} \mathrm{C}$ ) was recorded during admissions.

In our study, the mean value of WBC was $11.73 \pm 2.75$ and ranged (7.4 19.4). The mean value of CRP was $10.6 \pm 9.03$ ranged $(6-48)$. Normal CRP does not exclude infection and a raised CRP isn't specific and should not be depended upon to determine if pregnancy should be terminated; it should be used to identify early subclinical infection in addition to other parameters.

Similar results were reported by Giles et al. ${ }^{(17)}$. The median CRP (range 8-56 $\mathrm{mg} / \mathrm{L}$ ) was $9 \mathrm{mg} / \mathrm{L}$.

In the majority of our cases, 66 $(90.41 \%)$ of the Non-stress test was reactive versus non-reactive in only 7 $(9.59 \%)$.

Similar results were reported by Vintzileos et al. ${ }^{(18)}$ of the Thirty-two patients who acquired infection 25 (78.1\%) had non-reactive stress tests and the rest seven $(21.8 \%)$ had reactive tests. Of the 95 women who did not acquire an infection, $13(13.7 \%)$ had non-reactive non-stress tests, and the rest $82(86.3 \%)$ had reactive tests.

In our study, no urinary tract infection was noticed in the majority of studied cases $46(63.01 \%)$ versus $23(31.51 \%)$ had urinary tract infection while urine analysis not done in 4 (5.48\%) of cases.

Similar results were reported by Sultana et al. ${ }^{(11)}$. The major risk was a history of urinary tract infection in twenty-seven $(43.5 \%)$ cases with PPROM.

But in a study by Hackenhaar et al. (19). The lack of correlation between PPROM and urinary infections in pregnancy may be due to the complete treatment of urinary tract infection is most cases.
In our study, $71(97.26 \%)$ of cases received steroid therapy. Pharande et al. (16) reported that Antenatal glucocorticoids administration was markedly increased in Early-PPROM (95\%) and Late-PPROM (97\%) groups compared with No-PPROM (88\%) group.

But in our study, the majority of cases not received tocolytic therapy 53 (72.6\%). Also, Giles et al. ${ }^{(17)}$ reported that the percentage of cases given tocolysis was $30.3 \%$.

In our study, all cased treated with antibiotics either Dalacin in $64(87.67 \%)$ of them or combination of Dalacin 300 $\mathrm{mg}+\mathrm{IV}$ Cefotaxime $1 \mathrm{gm}$ in only 9 $(12.33 \%)$ of cases. The use of antibiotics in

Similar results were reported by Lee et al. ${ }^{(8)}$. The Giving clarithromycin, ceftriaxone, and metronidazole was correlated with more effective intra-amniotic inflammation/infection elimination and also more frequently prevented secondary intra-amniotic inflammation/infection than was found with a traditional antimicrobial therapy used in PROM.

In our study, the mean value of the latency period was $20.1 \pm 13.73$ days and ranged $(1-60)$. Phupong and Kulmala ${ }^{(20)}$ reported that a total of 231 cases of PPROM was included. Prolong latency periods $\geq 2$ and 7 days were achieved in $141(61 \%)$ and 54 (23.4\%) cases.

In our study, the majority of cases 63 (86.3\%) delivered by CS and only 10 $(13.7 \%)$ had a normal vaginal delivery. Aris et al. (12) recorded that PPROM cases were 2.2 times more prone to be delivered by instrument, 1.8 times more prone to be delivered by cesarean section.

This contradicts the study by Dars et al. ${ }^{(15)}$ which reported the incidence of $12 \%$ of CS. But the incidence of vaginal delivery was $70 \%$ in another study by Al Riyami et al. ${ }^{(21)}$ 
In our study, the cause of CS delivery was PROM in $37(50.68 \%)$ of cases, $16(21.92 \%)$ had contractions, 8 $(10.96 \%)$ had chorioamnionitis while 5 $(6.85 \%)$ either due to Fetal distress or placental separation and $1(1.37 \%)$ Either due to breech or retroplacental hematoma.

About the indications for cesarean section in a study by Abdoulfattah and Ezzat ${ }^{(13)}$, fetal distress 45 cases with a percentage of ( $25.28 \%)$, progress failure 72 cases with a percentage of $(40.4 \%)$ and previous cesarean section (s) 61 cases with a percentage of (34.2\%).

In our study, the majority of delivered baby 40 (54.79\%) had an Apgar score $<6$ versus only $33(45.21 \%)$ had a score $>6$. Among 62 neonates, Sultana et al. ${ }^{(11)}$ found that 5 minute Apgar score of $<7$ were noticed in $30.6 \%$ of cases, but dissimilar findings by Rawat et al. ${ }^{(\mathbf{1 0})}$ as Apgar score was $>7$ in $92 \%$ at 1 minute and in $94 \%$ at 5 minutes PROM cases.

In our study, the majority of delivered baby $42(57.53 \%)$ admitted in NICU while only 31 (42.47\%) not needs NICU admissions.

Similar results were reported by Sultana et al. ${ }^{(11)}$ Among 62 neonates $15(50 \%)$ babies were referred to NICU, but a lower incidence was reported by Abdoulfattah and Ezzat ${ }^{(13)}$, admission to neonatal intensive care unit (NICU) 53 cases with incidence $10.07 \%$.

There was a non-significant difference, in our study, among patients groups received tocolysis and those not received tocolytic therapy in latency periods $(20.9 \pm 12.63 \& 19.79 \pm 14.23$ respectively $\& \mathrm{p}=0.527)$.

But in disagreement, Phupong and Kulmala ${ }^{(20)}$ found that tocolysis was significant factors correlated with latency period more than or equal to 2 days.
The use of tocolytics on patients with preterm PROM is controversial. Conde-Agudelo et al. (22) found that nifedipine was associated with a significant increase in pregnancy prolongation.

In our study, $55 \%$ and $58.5 \%$ of received tocolysis and those not received tocolytic therapy respectively admitted to NICU without significant difference between patients groups $\mathrm{p}=0.788$.

This result was similar to Crowther et al. ${ }^{(23)}$ who compared magnesium sulfate with placebo or no tocolytic treatment (346 women). A non-significant difference was present among groups for the need for NICU admission.

In contrast, Conde-Agudelo et al. (22) found that nifedipine was correlated with a significant decrease in then need for NICU admission.

\section{CONCLUSION}

PROM once occurred; the debate is whether to terminate the pregnancy at the current gestational age or not, as prolongation of pregnancy will increase the risk of intrauterine infection and on the other hand delivery will expose the baby to the risks of preterm delivery and complications. Therefore, effective detection of existing or imminent complications and individualization of treatment based on gestationnal age and the occurrence or probability of such complications are currently best hoped to maximize fetomaternal outcomes in PROM patients.

\section{REFERENCES}

1. ACOG Committee on Practice Bulletins-Obstetrics. Clinical management guidelines for obstetrician-gynecologists. (ACOG Practice Bulletin No. 80: premature rupture of membranes). Obstet Gynecol. 2007; 109: 10071019.

2. Mercer BM, Goldenberg RL, Meis PJ, et al. The Preterm Prediction Study: prediction of preterm premature rupture of membranes through clinical findings 
and ancillary testing. The NICHD Maternal-Fetal Medicine Units Network. Am J Obstet Gynecol. 2000; 183: 738-745.

3. Mulhair L, Carter J, Poston L, Seed P, Briley A. Prospective cohort study investigating the reliability of the AmnioSense method for detection of spontaneous rupture of membranes. BJOG 2009; 116: 313-8.

4. National Institute for Health and Clinical Excellence guidelines. NG 25, 2015.

5. Dale PO, Tanbo T, Bendvold E, et al. Duration of the latency period in preterm premature rupture of the membranes. Maternal and neonatal consequences of expectant management. European Journal of Obstetrics \& Gynecology and Reproductive Biology 1989; 30: 257262.

6. Mercer BM. Management of premature rupture of membranes before 26 weeks' gestation. Obstet Gynecol Clin North Am 1992; 19(2): 339-51.

7. Kibel M, Barrett J, Tward C, et al. The natural history of preterm premature rupture of membranes in twin pregnancies. The Journal of MaternalFetal \& Neonatal Medicine 2017; 30: 1829-1835.

8. Lee J, Romero R, Kim SM, et al. A new antibiotic regimen treats and prevents intra-amniotic inflammation/ infection in patients with preterm PROM. The Journal of Maternal-Fetal \& Neonatal Medicine 2016; 29: 2727 2737.

9. Mukharya $\mathrm{J}$ and Mukharya S. Comparative study of fetal and maternal outcomes of prelabour rupture of membranes at term. International Journal of Reproduction, Contraception, Obstetrics and Gynecology 2017; 6: 150.

10.Rawat R, Divedi P, Debbarma S, et al. A comparative study between active and expectant management of premature rupture of membranes at term on fetomaternal and perinatal outcome in rural population. Int $\mathbf{J}$ Reprod Contracept Obstet Gynecol 2018; 7: 2393-2398.
11.Sultana $\mathrm{S}$, Ishtiaq $\mathrm{S}$, Malik $\mathrm{U}$, et al. Maternal and perinatal outcome in preterm prelabour rupture of membranes. Pak J Surg 2019; 35: 73 77.

12.Aris I, Logan S, Lim C, et al. Preterm prelabour rupture of membranes: a retrospective cohort study of association with adverse outcome in the subsequent pregnancy. BJOG: An International Journal of Obstetrics \& Gynaecology 2017; 124: 1698-1707.

13.Abdoulfattah LE, Laila Ezzat. A Retrospective Study of Feto -Maternal Outcome in Premature Rupture of Membranes at Aswan University Hospital 2018; 110-113.

14. Assefa NE, Berhe H, Girma F, et al. Risk factors of premature rupture of membranes in public hospitals at Mekele city, Tigray, a case-control study. BMC Pregnancy Childbirth 2018; 18: 386.

15.Dars S, Malik S, Samreen I, et al. Maternal morbidity and perinatal outcome in preterm premature rupture of membranes before 37 weeks' gestation. Pakistan Journal of Medical Sciences 2014; 30: 626.

16.Pharande P, Mohamed AL, Bajuk B, et al. Preterm infant outcomes in relation to the gestational age of onset and duration of prelabour rupture of membranes: a retrospective cohort study. BMJ Paediatr Open 2017; 1: e000216.

17. Giles M, Garland S and Oats JJN. Management of preterm prelabour rupture of membranes: an audit. How do the results compare with clinical practice guidelines? Australian and New Zealand Journal of Obstetrics and Gynaecology 2005; 45: 201-206.

18.Vintzileos AM, Campbell WA, Nochimson DJ, et al. The use of the nonstress test in patients with premature rupture of the membranes. American journal of obstetrics and gynecology. 1986; 155: 149-153.

19. Hackenhaar AA, Albernaz EP and Fonseca TMV. Preterm premature rupture of the fetal membranes: association with sociodemographic factors and maternal genitourinary 
infections. Jornal de Pediatria. 2014; 90: 197-202.

20.Phupong V and Kulmala L. Factors associated with latency period in preterm prelabour rupture of membranes. The Journal of MaternalFetal \& Neonatal Medicine. 2016; 29: 2650-2653.

21.Al Riyami N, Al Ruheili I, Al Shezaw F, Al Khabori M. Extreme preterm premature rupture of membranes: Risk factors and feto-maternal outcomes.
Oman Medical Journal. 2013; 28(2): 108- 11.

22. Conde-Agudelo A, Romero $\mathrm{R}$ and Kusanovic JP. Nifedipine in the management of preterm labor: a systematic review and meta-analysis. Am J Obstet Gynecol 2011; 204: 134.e131-120.

23. Crowther CA, Hiller JE, and Doyle LW. Magnesium sulfate for preventing preterm birth in threatened preterm labor. Cochrane Database of Systematic Reviews, 2002. 